\title{
PATERNIDADE: UM ESTUDO SOBRE PESQUISAS DESENVOLVIDAS NO CONTEXTO BRASILEIRO.
}

Juliana de Castro Prado, Jorge Luís Ferreira Abrão

Universidade Estadual Paulista - FCL. Departamento de Psicologia Clínica, Assis-SP. E-mail: jujcp@hotmail.com

\section{RESUMO}

Este estudo tem por objetivo identificar e sistematizar as pesquisas que vem sendo produzidas a respeito do tema Paternidade no Brasil, buscando identificar os métodos utilizados nos artigos, a época e a região em que estes foram escritos, suas respectivas áreas de produção, e principalmente, o conteúdo dos mesmos. Utilizando-se da metodologia "Estado da Arte", foi encontrado o total de 35 artigos na base de dados eletrônicos Scielo, fazendo-se uso do descritor "paternidade". Os resultados apontam para significativa produção acadêmica, sendo destacadas, principalmente, nas áreas de Psicologia e Enfermagem. A paternidade vem ganhando espaço e importâncias nos estudos científicos, sendo os pais considerados importantes para o desenvolvimento dos filhos e também para as relações conjugais. A paternidade e o modelo familiar encontram-se ora arraigados a modelos antigos, ora aderindo a novos comportamentos. Palavras-chave: Paternidade; pai; modelos familiares.

\section{FATHERHOOD: A STUDY ABOUT BRAZILIAN RESEARCHES DEVELOPED IN BRAZIL.}

\begin{abstract}
This study aimed to identify and systemize what is being produced about the subject Fatherhood in Brazil, prioritizing topics such as: the researches' methodology, the period and the place the researches were performed, and mainly, its content. Using the methodology "State of the Art", was found a total of 35 articles in the electronic database Scielo, making use of the descriptor "fatherhood".The results point out to the significant academic production, highlighting the Psychology and the Nursing areas. Fatherhood has been gaining importance in scientific studies, and parents are being considered important for children's development and for marital relations. It was also found that Fatherhood and the family model are now ingrained to older models and values, sometimes adhering to new behaviors.
\end{abstract}

Keywords: Fatherhood, father, family model. 


\section{INTRODUÇÃO}

Fruto de todas as transformações que a configuração familiar sofreu ao longo dos tempos, a figura e o papel do pai se encontram hoje em processo de transição.

A Paternidade é um fenômeno que foi pouco abordado durante as últimas décadas pelos pesquisadores, vindo a ser estudada, com maior consistência, segundo Brasileiro, Jablonski e Feres-Carneiro (2002), apenas a partir dos anos de 1980, que decorrente de diversas alterações ocorridas na sociedade durante este período, culminou na luta das mulheres por seus direitos e liberdade durante a Revolução Feminina.

Contribuindo com a entrada da mulher ao mercado de trabalho, este movimento colocou em cheque o lugar social do homem, bem como o modelo familiar patriarcal predominante da sociedade brasileira (BRUCHINI; RIDENTE, 1994; GOMES; RESENDE, 2004; PERUCCHI; BEIRÃO, 2007), corroborando o surgimento de novos arranjos familiares e uma paternidade contemporânea.

A crise da masculinidade tem levado um número de homens a refletir a respeito de suas experiências patriarcais e seus respectivos papéis no cenário doméstico e nas relações familiares. Se o modelo familiar atual da sociedade brasileira encontra-se em transformação, por conseguinte, as funções pré-estabelecidas para a paternidade também estão. Agora, da mesma forma que as mulheres ingressam no mercado de trabalho, função esta considerada até então masculina, os homens passam a compartilhar de algumas tarefas domésticas e também da educação de seus filhos (FREITAS et al., 2009).

Todas estas transformações que vêm acontecendo no modelo familiar brasileiro repercutem e influenciam as relações conjugais e, consequentemente, o papel ocupado pelos pais dentro da família. Por esta óptica, pode-se afirmar que a Paternidade encontra-se em transição e, sentimentos de ambiguidade passam a operar no sexo masculino, uma vez que seu papel não é mais, obrigatoriamente, o de provedor (PERUCCHI; BEIRÃO, 2007).

Apesar do recente interesse por parte de pesquisadores em se estudar as mudanças de expectativas em relação ao papel paterno, pouco ainda se sabe a respeito de como os pais estão lidando e vivenciando tais mudanças, de que maneira estes pais se avaliam neste papel e quais sentimentos apresentam em relação à paternidade (SILVA; PICCININI, 2007). Isto nos leva a indagar a respeito do pequeno, porém crescente, número de trabalhos produzidos no Brasil sobre a paternidade, bem como o recente interesse neste estudo, por parte de pesquisadores, dando importância às 
transformações e implicações deste tema no modelo familiar contemporâneo.

Por não existir até o momento um trabalho que tenha sistematizado os estudos produzidos sobre o tema paternidade, tornase difícil afirmar precisamente o que vem sendo estudado sobre este assunto no Brasil, bem como os métodos de pesquisa utilizados para alcançar este objetivo. Diante de tais considerações, este artigo teve como objetivo identificar e sistematizar as pesquisas que vem sendo produzidas a respeito do tema Paternidade, buscando averiguar os métodos utilizados nas pesquisas, a época e a região em que tais pesquisas foram realizadas, as áreas de produção de cada pesquisa, e principalmente, o conteúdo teórico de cada uma delas.

Para darmos forma ao objetivo proposto acima, organizamos este artigo da seguinte maneira: primeiramente será apresentada a metodologia utilizada na construção deste estudo, seguida dos resultados quantitativos obtidos a partir da tabulação das pesquisas encontradas. Posteriormente, segue-se a análise qualitativa das mesmas, permitindo 0 agrupamento e a sistematização a partir de temas centrais.

\section{MÉTODO}

Através do método bibliográfico denominado de "Estado da Arte" (Ferreira, 2002) buscou-se identificar, mapear, delimitar e discutir o que se tem produzido a respeito de um determinado tema: a Paternidade, no caso deste estudo. Optou-se por um levantamento de artigos brasileiros na base de dados Scielo, utilizando-se a palavra-chave Paternidade, independente da área do conhecimento em que os mesmos fossem encontrados. A escolha por artigos, e não por teses, se deu na intenção de uma maior amplitude e abrangência de trabalhos encontrados sobre o assunto.

Com a exclusão de pesquisas que se afastavam da temática paternidade, foi analisado o total de 35 artigos. Destes, dois deles foram provenientes de dissertações de mestrado, e outros dois, de teses de doutorado.

Seguido ao levantamento dos artigos, estes foram analisados de forma quantitativa, com a finalidade de se obter dados mais objetivos. Foram priorizados nos aspectos como: número de publicações por ano; local/região em que foram produzidos; metodologias utilizadas; 0 que se tem produzido sobre o tema; área de produção e revistas em que foram publicados. Posterior à análise quantitativa das pesquisas, foi realizada com as mesmas, uma análise qualitativa para a sistematização dos dados 
referentes aos estudos produzidos sobre Paternidade, conforme proposto na metodologia "Estado da Arte".

\section{RESULTADOS}

\subsection{Sobre os artigos pesquisados}

Apreciando nos trabalhos

encontrados o número de artigos publicados por ano; o local/região em que foram produzidos; as metodologias utilizadas; o que se tem produzido sobre o tema Paternidade; a área de produção de cada pesquisa e as revistas em que foram publicadas, foram encontrados os seguintes resultados:

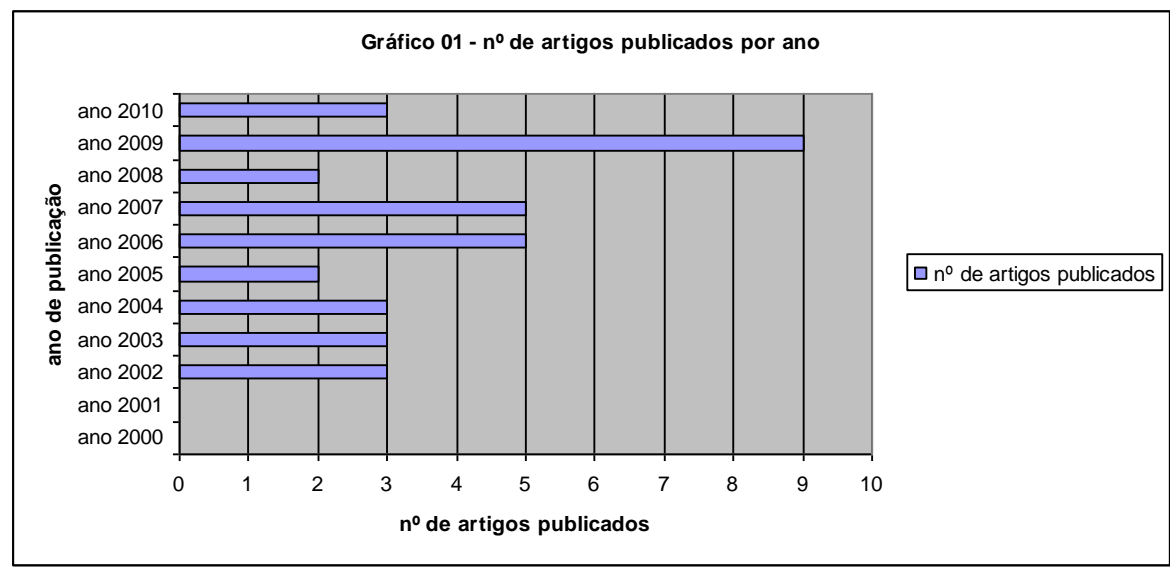

Conforme demonstrado no gráfico acima, com relação ao período em que os artigos foram publicados, estes se encontram entre o ano de 2002 a 2010. Com o total de nove artigos publicados, 2009 foi o ano em que mais houve publicação a respeito da Paternidade. Seguindo, com a publicação de cinco artigos para cada ano, 2006 e 2007 ocuparam o segundo lugar no que se refere ao ano em que mais se publicou artigos sobre este mesmo tema.

O ano de 2010 ficou em terceiro lugar, com apenas três artigos publicados sobre o tema, juntamente com o ano de 2002, 2003, 2004. Em último lugar, com apenas duas publicações, o ano de 2008 diferenciou-se dos demais anos ocupantes do terceiro lugar, com a publicação de um artigo a menos. 


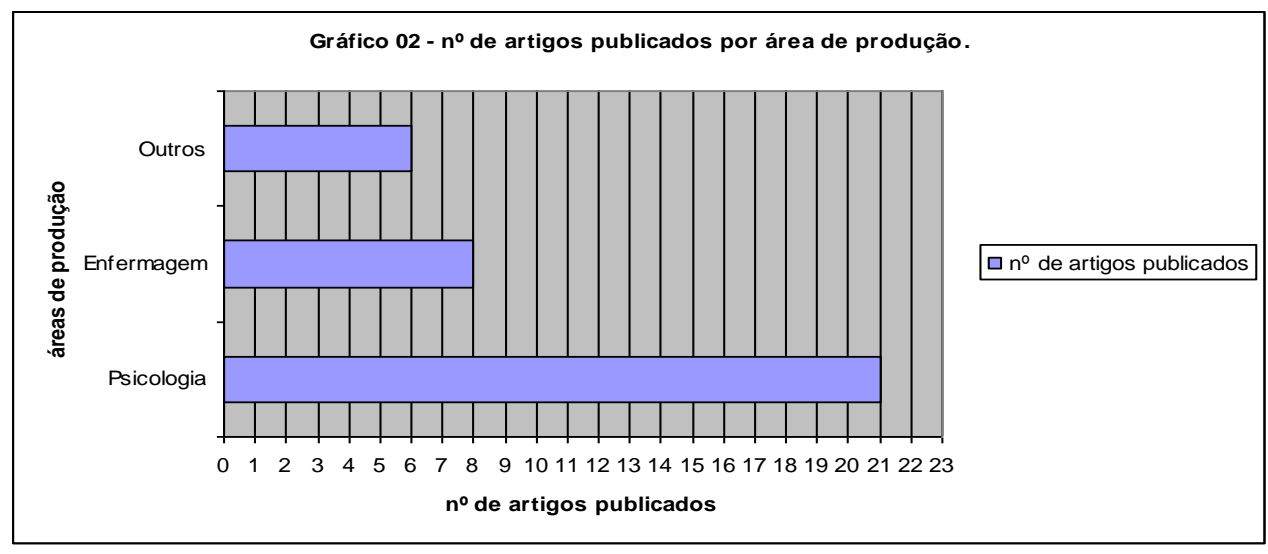

Com relação às áreas de produção dos artigos, demonstrados no gráfico a cima, vinte e um destes trabalhos pertencem à área de Psicologia, oito pertencem à área de Enfermagem e seis encontram-se pertencentes à área de Medicina Social, Nutrição, Ciências Biológicas, Genética, Sociologia e Saúde Coletiva.

Foi observado que quanto aos locais/regiões em que os artigos foram publicados, a maioria dos artigos foi proveniente da Universidade Federal do Rio Grande do Sul (Porto Alegre). A Universidade Federal de Pernambuco, Universidade Federal do Rio de Janeiro, e Universidade Federal do Espírito Santo também estiveram presentes, no entanto, em um número menor quando comparados às publicações pela Universidade Federal do Rio Grande do Sul.

Quanto às revistas em que os artigos foram mais publicados, as que se sobressaíram, com a publicação de quatro artigos cada, foram: Psicologia Clínica,
Estudos de Psicologia, e Caderno de Saúde Pública.

\section{2. Sistematização dos temas encontrados}

Ao analisar os trinta e cinco artigos produzidos sobre o tema Paternidade considerando os tópicos estudados em cada pesquisa, bem como as formas isoladas utilizadas na abordagem deste assunto, os trabalhos foram agrupados e classificados em treze temáticas, sendo elas: 1) Envolvimento paterno no processo de amamentação; 2) Paternidade e o processo de adoção; 3) Participação paterna no nascimento do filho; 4) Paternidade e o processo de gestação; 5) Paternidade na adolescência; 6) Paternidade e o discurso de mídia; 7) Paternidade e Psicanálise; 8) Vivência, experiência e sentimentos ligados à paternidade em adultos do sexo masculino; 9) Paternidade e a produção acadêmica; 10) Paternidade na perspectiva de jovens universitários; 11) Paternidade na perspectiva de mulheres chefes de família; 12) Paternidade e o teste 
de DNA; e 13) Paternidade brasileira no

demonstrando.

século 21. Abaixo segue o gráfico

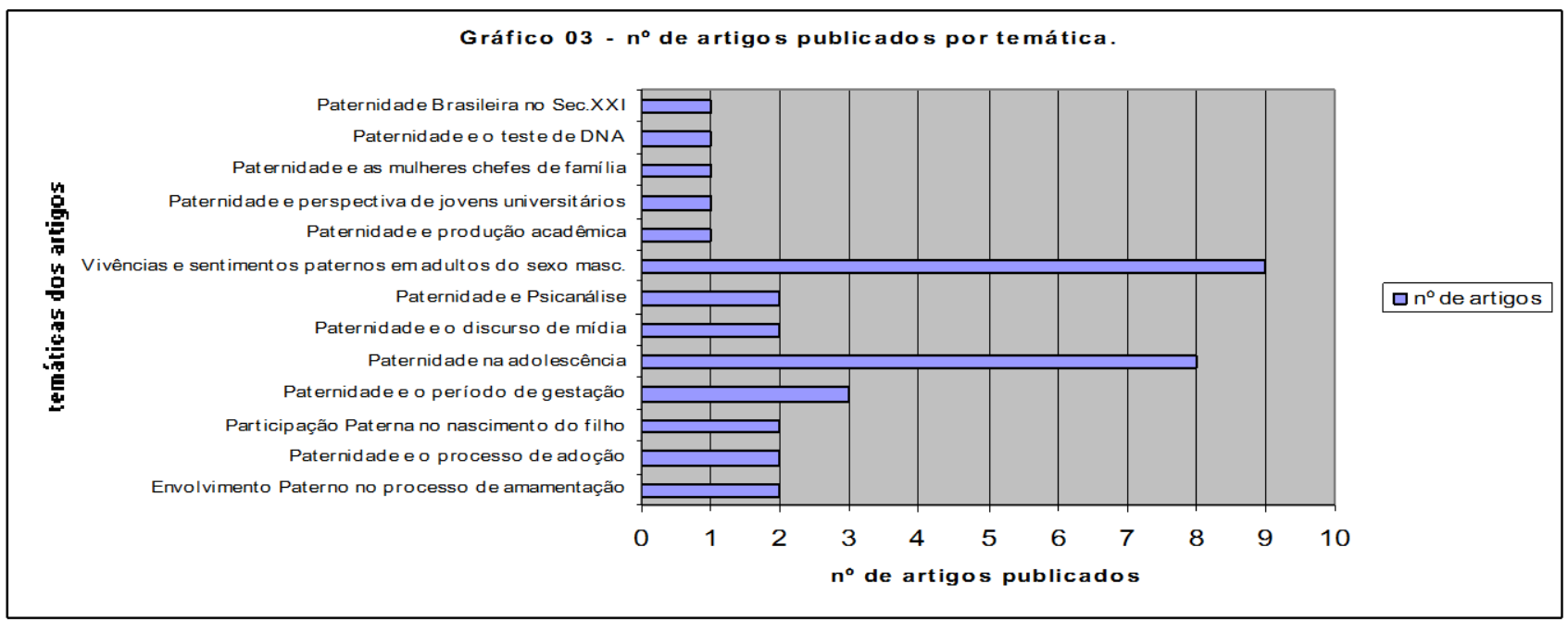

Com relação ao tema "Paternidade $e$ o processo de adoção", foram encontrados dois artigos nos quais o primeiro deles, um estudo de caso, preocupou-se em investigar as significações atribuídas à paternidade durante o processo de adoção de um bebê (ANDRADE; COSTA; ROSETTI-FERREIRA, 2006). Neste artigo, foram realizadas entrevistas com dois homens casados, adotantes de bebê. Foi utilizada como referencial teórico-metodológico a Rede de Significações em interlocuções com estudos sobre adoção, gênero e família.

O segundo artigo, por sua vez, buscou compreender o processo de construção da paternidade e maternidade, bem como suas respectivas significações, em um processo de adoção tardia de duas irmãs (COSTA; ROSETTI-FERREIRA, 2007). De forma similar ao artigo anterior, o referencial teórico- metodológico utilizado foi o da Rede de significações, agora em interlocução com o referencial da produção de sentidos nas práticas discursivas.

Ao comparar os dois artigos encontrados sobre esta temática, foi possível verificar que exercer a paternidade é uma questão fundamental para que se considere ter uma família completa. $\mathrm{O}$ fato de os pais se mostrarem interessados em adotar demonstra o quanto o relacionamento entre pai e filhos é essencial para que a constituição de uma família seja atingida. Por mais que os pais sejam pais adotivos, a gratificação em serem considerados pais é notória. A paternidade, ainda que adotiva, faz parte do desejo e realização de atingirem mais um estágio da vida adulta: formar uma família. 
Observou-se também que apesar de alguns pais terem apresentado um discurso igualitário em relação à participação no cuidado do filho, as mães ainda são as principais responsáveis por esta tarefa, e pelos afazeres domésticos. A estabilidade financeira e emocional por parte dos pais se fez presente como um quesito importantíssimo antes de se pensar em ter um filho.

Em relação à temática "Participação paterna no nascimento do filho", foram encontrados dois artigos nos quais o primeiro procurou investigar as dificuldades institucionais e as motivações dos casais na participação do parto (CARVALHO, 2003). Neste artigo de pesquisa etnográfica, dividida em suas etapas, foi realizada uma observação-participante do trabalho de parto e do parto, e posteriormente, entrevistas com pais participantes do parto.

O segundo artigo, por sua vez, traz a interpretação de um parto hospitalar através da perspectiva do pai, levando em consideração as vivências culturais do individuo. O relato do material analisado é apresentado na forma de uma narrativa de contos de fada, sendo comparado e analisado com o conto da Chapeuzinho Vermelho (LUZ; ZANETTI, 2003).

Os dois artigos trazem em comum a importância da participação do pai no parto do filho, que além de ser um direito pouco conhecido por muitos deles, é uma forma de já exercer a experiência de ser pai, e também de servirem de apoio às gestantes. Além deste aspecto, os dois artigos ressaltam a dificuldade, por parte das equipes de saúde, em permitir aos pais a participação do parto. A proposta de incentivo à participação masculina neste processo é sugestão nos dois artigos. O medo e o despreparo mediante a situação de se tornar pai foi manifestado pelos participantes das duas pesquisas.

Em relação à temática "Paternidade no processo de gestação" foram encontrados três artigos, no qual o primeiro deles, de referencial psicanalítico, buscou investigar as expectativas e sentimentos de futuros pais em relação ao seu bebê, ainda no processo de gestação (PICCININI et al., 2009). Foram entrevistados 35 pais que esperavam o seu primeiro filho e, posteriormente, as entrevistas foram analisadas mediante a Análise de Conteúdo, similarmente os dois artigos encontrados sobre este tema.

O segundo artigo teve como objetivo compreender a transição para a paternidade, investigando-se as expectativas e sentimentos de pais cujas mulheres estavam no nono mês de gestação, e posteriormente, a experiência de paternidade após o nascimento do bebê (KROB; PICCININI; SILVA, 2009). Os participantes desta pesquisa foram homens casados, entrevistados no nono mês 
de gestação da esposa, e dois meses depois que o filho havia nascido.

O terceiro artigo, um estudo de caso instrumental, buscou descrever a vivência da gravidez do primeiro filho, sob a perspectiva paterna. Foram realizadas cinco entrevistas com cinco homens que seriam pais do primeiro filho (BORNHOLDT; WAGNER; STAUDT, 2007).

Ao compararmos os três artigos encontrados sobre esta temática, fica evidente que o nascimento de um filho é um acontecimento que traz tanto sentimentos de alegria quanto de preocupação. A gestação foi vista pelos pais como um momento em que podem fantasiar sobre o futuro bebê, considerando possibilidades tanto boas quanto ruins (alguma complicação no parto, malformação, etc.). Verificou-se que a participação na gestação do filho traz além de preocupações futuras, responsabilidades novas. Tudo passa a ser voltado aos interesses do bebê. O exercício da paternidade se mostrou fortemente ligado às questões financeiras, como sendo a principal função a ser desempenhada pelo pai.

Quanto ao tema "Envolvimento paterno no processo de amamentação", dois artigos foram encontrados, sendo o primeiro, um estudo descritivo e exploratório, tendo como participantes dezessete casais, entrevistados durante o período em que seus filhos se encontravam entre seus a oito meses de idade, com o objetivo de evidenciar as vivências, comportamentos e conhecimentos do pai no processo de amamentação (PONTES; ALEXANDRINO; OSÓRIO, 2009).

O segundo artigo, escrito pelos mesmos autores (PONTES, ALEXANDRINO; OSÓRIO, 2009), parte do trabalho anterior para desvendar eixos norteadores e, a partir deles, elaborar uma proposta de incentivo para a participação dos pais no processo de amamentação, buscando estratégias nas diversas fases da vida destes pais, desde a infância até tornarem-se pais. O conteúdo das entrevistas semiestruturadas foi analisado e interpretado através da Análise de Conteúdo e referencial teórico histórico, social e cultural da paternidade.

Observou-se que os conhecimentos, comportamentos, vivências e sentimentos relacionados ao processo de amamentação sob a perspectiva masculina estão vinculados à socialização do homem e da mulher, centrada no corpo biológico, evidenciando que o amamentar é uma atividade exclusivamente feminina e que este pensamento masculino pode estar vinculado a aspectos históricos, sociais e culturais, quando relacionados à paternidade. Entretanto, por mais que seja uma visão que define a amamentação como única da mulher, a proposta de incentivo à 
participação dos pais no processo de amamentação de fez presente.

A temática "Paternidade e a produção acadêmica", por sua vez, foi encontrada em apenas um artigo, que buscou verificar a produção de artigos nacionais e internacionais, produzidos sobre o tema Paternidade, no período de 2000 a 2007 (SOUZA; BENETTI, 2009) nas bases de dados: LILACS, Scielo, Web of Science, MEDLINE e Redalyc.

Os resultados demonstraram um número significativo de artigos nacionais e internacionais produzidos sobre o tema Paternidade. Destacando-se os países Estados Unidos, Inglaterra e Brasil, a Paternidade tem sido um importante para a compreensão das relações familiares, de fundamental importância para implementação de políticas públicas de apoio às famílias de diferentes contextos (SOUZA; BENETTI, 2009).

Em relação à temática "Paternidade sob a perspectiva de jovens universitários", foi encontrado também apenas um artigo com este tema, que procurou enfatizar a paternidade através da visão de oito jovens entrevistados, que se encontravam fazendo um curso superior. Considerou-se a visão que estes jovens tinham em relação à sua criação e educação para a paternidade, bem como a maneira pela qual as instituições família, amigos e escola influenciam o modo pensar sobre a paternidade (PEROSA; PEDRO, 2009).

Esta pesquisa, de caráter descritivo, qualitativo e exploratório, verificou com as entrevistas analisadas através da Análise Temática, que a família, o papel do pai destes jovens, a estabilidade financeira, a importância da companheira e o papel do matrimônio são de fundamental importância para que a construção da Paternidade aconteça de forma saudável (PEROSA; PEDRO, 2009). O pai dos entrevistados foi considerado modelo a ser seguido e superado. As condições emocionais, afetivas e, principalmente financeiras, foram os quesitos tidos como necessários para que a etapa da Paternidade fosse atingida de forma gratificante pelos entrevistados.

Sobre a temática "Paternidade na perspectiva de mulheres chefes de familia", foi encontrado um artigo, relato de uma pesquisa que procurou investigar o significado de Paternidade para dez mulheres responsáveis pelo sustento de suas respectivas famílias (PERUCCHI; BEIRÃO, 2007). Com a entrevista (semiestruturada) das participantes e, posteriormente, a análise das mesmas através da Análise de Conteúdo, verificou-se que por mais que estas mulheres ainda relacionem a figura paterna a uma figura de autoridade, a paternidade estaria ligada à participação em tudo o que diz respeito à educação dos filhos e também ao 
campo da afetividade. A tarefa provedora seria uma tarefa a ser compartilhada por ambos os cônjuges (PERUCCHI; BEIRÃO, 2007).

A temática da "Paternidade na adolescência" foi uma das temáticas que mais foram encontradas no decorrer desta pesquisa. Foram localizados sete artigos que abordam a Paternidade na adolescência, sob diversas perspectivas e metodologias (a que mais se sobressaiu foi a entrevista, analisada mediante Análise de Conteúdo). A primeira perspectiva engloba a gravidez na adolescência, priorizando as noções de contracepção e gravidez entre pais adolescentes (CABRAL, 2003). Neste artigo, a anticoncepção foi tida como responsabilidade feminina e a assunção da paternidade na adolescência, como consolidação da imagem de homem adulto, responsável e maduro.

Outro artigo procurou estudar a vivência da paternidade adolescente sob a perspectiva dos pais do adolescente que se tornara pai (MEINCKE; CARRARO, 2009). Os pais destes adolescentes procuraram se adaptar à nova situação e exercer a paternidade com os filhos que agora se tornavam pais. Por mais que sentimentos negativos com relação à nova situação do filho estivessem presentes (o medo e a preocupação por serem ainda adolescentes), sentimentos positivos se sobressaíram, sendo eles, principalmente, o apoio, amor afeto e carinho.

Um terceiro artigo estudou o processo de separação-individuação em adolescentes no período de transição para a paternidade (LEVANDOWSKI; PICCININI; LOPES, 2009). Verificou-se que a paternidade na adolescência, apesar de impedir que algumas atividades propícias desta fase sejam executadas, não traz apenas repercussões negativas, podendo promover o desenvolvimento de aspectos pessoais e emocionais, uma vez que agora estes jovens são chamados a assumir comportamentos referentes à vida adulta.

Dois artigos procuraram estudar a paternidade na adolescência de forma geral, considerando as vivências e significações atribuídas à paternidade para estes pais adolescentes (LUZ; BERNL, 2010; TRINDADE MENANDRO, 2002). Verificaram-se aspectos relacionados à vulnerabilidade com relação à paternidade pelos adolescentes, bem como o abandono escolar em decorrência da inserção no mercado de trabalho.

No artigo de Luz e Bernl (2010), a paternidade mostrou-se ligada mais a um envolvimento sexual, fazendo-se inexistente um planejamento futuro. Por outro lado, no artigo de Trindade e Menandro (2002), a paternidade esteve ligada além da função provedora, aos cuidados de educar e dar carinho ao filho. 
Outro artigo, de Levandowski e Piccinini (2002), estudou a interação pai-bebê entre pais adolescentes e adultos, no intuito de verificar algumas semelhanças e diferenças presentes entre estas duas fases da vida. Não houve diferença significativa na interação pai-bebê entre pais adolescentes e adultos, demonstrando que a idade não é determinante do grau de responsabilidade dos pais diante dos cuidados relacionados ao bebe.

O último artigo, dos mesmos autores, Levandowski e Piccinini (2006), por sua vez, enfatizou as expectativas e sentimentos de futuros pais adolescentes e adultos, com o mesmo intuito do artigo citado anteriormente. Verificou que tanto adolescentes quanto adultos demonstraram expectativas positivas diante do exercício da paternidade e com relação ao bebê, por mais que a insegurança diante da capacidade de exercer o papel de Pai estivesse presente. Os resultados também sugerem que a idade não é decisiva na determinação das expectativas e sentimentos relacionados à transição para a paternidade.

Ao analisar estes sete artigos verificou-se que, além da vulnerabilidade diante deste novo ocorrido, a paternidade na adolescência, por mais que impedisse que estes adolescentes exercessem atividades pertencentes a este período de vida, promove crescimento e desenvolvimento de aspectos pessoais e emocionais destes adolescentes, que agora são chamados a assumir novas responsabilidades e comportamentos ligados à vida adulta.

A inserção no mercado de trabalho e, conseguintemente a função provedora, ainda estiveram relacionadas ao papel paterno. 0 apoio dos pais destes adolescentes foi tido como fundamental para que estes jovens pais exercessem com sucesso esta função importante na vida de cada um.

A temática "Vivências, sentimentos, expectativas e experiências da Paternidade em adultos do sexo masculino" foi a que mais se sobressaiu quanto aos temas mais trabalhados nos artigos. Foram encontrados nove artigos dentro desta temática, utilizando-se das mais diversas metodologias. Dentre esta variedade, a que mais se fez presente foi a Etnografia.

Um dos artigos, de revisão bibliográfica, procurou estudar a paternidade, considerando a relação entre pais e filhos após a separação conjugal (DANTAS; JABLONSKI; FÉRES-CARNEIRO, 2004). Verificou com este artigo que além do relacionamento do pai com a ex-mulher ser importante para tranquilidade e segurança dos filhos, o papel do pai no relacionamento com filho é de extrema importância. Com o divórcio, detectou-se um afastamento dos filhos, por parte dos pais, que ao morarem em residência separada da dos filhos ou 
constituírem outra família (tendo agora que assumirem outras responsabilidades) não passam tempo suficiente com os filhos, abalando a relação pai-filho.

Outro artigo, por sua vez, buscou pesquisar o pai e todo o sentimento envolvido ao ser convidado a suprir as demandas de uma família contemporânea, utilizando-se como método de pesquisa, o método clínico (GOMES; RESENDE, 2004). O pai contemporâneo foi visto como um pai mais presente e identificado com as exigências contemporâneas da família, expondo seus sentimentos e se opondo ao modelo tradicional de distanciamento entre o físico e o afetivo.

Os sentimentos sobre a paternidade e o envolvimento paterno na criação dos filhos também foram investigados, através de um estudo qualitativo e análise de conteúdo (SILVA; PICCININI, 2007), que revelou que de forma geral, os pais acreditavam que sua participação na vida da criança era de grande importância e se sentiam realizados exercendo a função de pai.

Outro artigo buscou analisar os significados atribuídos à paternidade por homens que eram pais, através do enfoque teórico de Gênero (FREITAS et al., 2009). A participação paterna no cuidado de crianças pequenas também fez parte desta temática, através de um estudo etnográfico, observação participante e entrevistas
(BUSTAMANTE; TRAD, 2005). Ficou demonstrado que a participação paterna se resumia em três aspectos, sendo eles: a educação dos filhos, sendo o pai de papel fundamental; a preservação da integridade, vista como obrigação de todos os integrantes da família; e os cuidados corporais em relação à criança (banho), tidos como exclusivos da função materna.

As experiências e vivências paternas também foram estudadas através da perspectiva de pais que viviam no subúrbio ferroviário (BUSTAMANTE; TRAD, 2005). De cunho etnográfico, através da observação participante e entrevistas semiestruturadas, observou-se que sentir-se pai não estava relacionado ao laço consanguíneo com a criança, mas sim com a qualidade da relação que o pai apresentava com sua companheira.

A experiência do pai no cuidado e convivência com o filho também foi estudada em casos de filhos prematuros (TRONCHIN; TSUNECHIRO, 2006). Esta pesquisa apresentou as vivências transformadoras na vida dos pais entrevistados, através de duas situações. A primeira situação (intrahospitalar), período em que o filho foi levado para a UTI neonatal, e posteriormente, ao berçário. A segunda situação (extrahospitalar), período em que o filho agora se encontrava em casa e com os pais.

Foi encontrado também um artigo de revisão bibliográfica sobre a paternidade no 
contexto da depressão pós-parto materna (SILVA; PICCININI, 2009). Ficou comprovado, de maneira geral, que o pai, na medida em que se mostre envolvido de forma mentalmente saudável, pode diminuir a influência e impacto da depressão pós-parto materna na esposa e no relacionamento e criação do filho.

Por fim, o último artigo sobre esta temática busca compreender a vivência masculina no "sentirem-se pais", através do olhar de Gênero (FREITAS; COELHO; SILVA, 2007). Foi evidenciado que os participantes desta pesquisa, no momento em que foram notificados da gravidez de suas respectivas esposas, sentiram a paternidade de forma diferente. Alguns ainda reproduziam o modelo tradicional de pai, mantendo-se distante de se acharem pais durante 0 período de gravidez. Estes só se sentiram pais após o nascimento do bebê. Outros, por outro lado, evidenciaram o modelo do "novo pai", agora mais participativo e envolvido afetivamente com o filho e com a esposa, desde o período da gravidez.

Ao analisar os nove artigos relacionados a esta temática, fica claro que a paternidade está relacionada às vivências e experiências que estes "novos" pais tiveram, ainda enquanto filhos, com seus próprios pais. Os "novos" pais que tiveram um relacionamento frio e distante com os pais na infância, optam por comportamentos opostos aos que vivenciaram, mostrando-se interessados em estabelecer um relacionamento afetivo com seus filhos. Por outro lado, o modelo tradicional de pai ainda é reproduzido, ligando a função paterna ao quesito financeiro, sendo exclusivamente feminina a responsabilidade de cuidado corporal do filho.

Estas divergências podem ser observadas através do fato de alguns pais só se sentirem pais após o nascimento dos filhos, enquanto que outros, ao participarem de todo o período gestacional de seu filho, já se consideravam exercendo a função paterna.

Sobre a temática "Paternidade e a Psicanálise" foram encontrados dois artigos, sendo os dois de caráter bibliográfico. O primeiro deles estuda a castração e seus destinos na construção da Paternidade (MOREIRA; BORGES, 2010), explicando que o caminho até a paternidade implica reviver o complexo de Édipo, colocando mais uma vez o seu desejo à prova e acordando conflitos adormecidos. Este caminho de volta ao Édipo leva o homem ao encontro com a castração, e consequentemente, às perdas narcísicas. Apenas os homens que suportam o primeiro impacto de ser pai e sustentam esse lugar, conseguem transmitir aos filhos muito mais que heranças genéticas.

O segundo artigo estuda a função do pai na psicanálise, através de sua relação de 
afiliação e posterior afastamento da ética religiosa em que é fundada, partindo da ética judaico-cristã da paternidade (MARTINELLI; LO BIANCO, 2006). Evidencia-se uma ética psicanalítica da paternidade na qual o mandamento do pai instaura a cisão do sujeito e o conflito que o constitui como aquele que vive bem no mal.

A paternidade também foi abordada através da temática "Paternidade e o teste de $D N A^{\prime \prime}$, que considerando a incidência de um número alto de testes de paternidade (DNA) em laboratórios públicos e clínicas particulares do Brasil, foram feitas reflexões quanto à inserção das esferas médica e jurídica, e sua influência nas relações de gênero e parentesco na sociedade contemporânea (FONSECA, 2004).

Por mais que o teste de DNA seja um meio de se comprovar de fato a paternidade, longe de trazer tranquilidade quanto à função de pai, este estudo demonstrou que o teste tem despertado dúvidas, principalmente naqueles pais provenientes de classe média, que não tendo condição de sustentar o filho (exercer a função de provedor), negam a paternidade ao filho (FONSECA, 2004).

A "Paternidade e o estudo de mídia" foi uma temática que também surgiu no decorrer das análises dos artigos, na qual foram encontrados dois artigos (de caráter bibliográfico) publicados sobre a importância da paternidade, utilizando-se o discurso de mídia. O primeiro artigo mostra, através da apresentação de um comercial de televisão, como os diferentes aspectos da cultura contemporânea atravessam e influenciam a temática do pai (HENNINGEM; GUARESCHI, 2002). Neste artigo, a concepção de paternidade está relacionada à construção social. Discutem-se as diversas possibilidades que os Estudos Culturais podem proporcionar à Psicologia Social, especialmente sobre o tema paternidade.

O segundo artigo discute a paternidade através de resultados de pesquisa que buscou conhecer o que vem sendo produzido sobre paternidade na mídia, bem como os efeitos destas nos modos de subjetivação. Este artigo considera que, estando a criança em processo de desenvolvimento, a presença do pai é essencial para que ela tenha um crescimento favorável (HENNINGEM, 2010).

Por fim, a temática "Paternidade no século XXI" foi encontrada em apenas um artigo (de caráter bibliográfico), que buscou analisar a paternidade em relação ao exercício do reconhecimento geracional, considerando a dimensão formal-legal e a dimensão afetivo-social, que colocam ao paicidadão, demandas políticas com a perspectiva de uma democracia expandida. Foi verificado que o não reconhecimento paterno de crianças brasileiras reflete a 
persistência de antigas práticas patriarcais, nas quais o arbítrio masculino foi - e tem se mantido - naturalizado (THURLER, 2006).

\section{DISCUSSÃO}

A partir dos trinta e cinco artigos encontrados, bem como suas diversas temáticas, pôde-se constatar, conforme apontam Silva e Piccinini (2007), o recente interesse por parte dos pesquisadores, no estudo da Paternidade e sua importância.

Partindo das pesquisas encontradas nos artigos, o tema que mais se sobressaiu esteve relacionado às vivências, sentimentos, expectativas e experiências da Paternidade. Os artigos não pertencentes a esta temática abordavam a paternidade subordinando-a a temas específicos. Entretanto, ao se falar sobre Paternidade, o que mais vem sendo estudado e considerado essencial, são às vivencias dos pais nesta nova fase. Conforme Silva e Piccinini (2007) apontam, tem-se dado agora, uma importância maior ao discurso e experiência dos pais, considerando-os, além das mães, importantíssimas figuras tanto no desenvolvimento da criança, como no desenvolvimento pessoal de cada um deles.

Verificou-se que por mais que o discurso da maioria dos pais participantes das pesquisas fosse um discurso que promovesse a igualdade nas funções desempenhadas por cada integrante da família, este ainda encontra-se arraigado ao modelo familiar patriarcal, onde a principal função caracterizadora da paternidade é a provisão econômica. Este achado é confirmado por Brasileiro, Jablonski e FeresCarneiro (2002) e por Bruchini e Ridenti (1994), que afirmam que a família dominante no Brasil é composta por um casal e seus respectivos filhos vivendo sob um mesmo teto no qual o homem é tido como provedor da família, enquanto sua esposa tem responsabilidade nos cuidados da casa e dos filhos.

Por outro lado, esta tendência começa a ser modificada com o surgimento mais frequente de outros modelos familiares. Famílias onde as mulheres detinham a função de provedora também se fizeram presentes neste estudo, contribuindo com o argumento de Freitas et al.(2009), além de influenciarem tanto 0 modelo familiar brasileiro predominante (nuclear), quanto as relações conjugais e o papel ocupado pelo pai dentro da família (PERUCCHI; BEIRÃO, 2007).

Uma vez que estas influências femininas impactaram de maneira direta e indireta o papel masculino na família, podese afirmar, conforme Perucchi e Beirão (2007) sugerem, que a Paternidade encontrase em transição e, consequentemente, sentimentos de ambiguidade passam a operar no sexo masculino, uma vez que seu papel não é mais, obrigatoriamente, o de provedor. 
Corroborando tal afirmação, foram encontrados casos de pais que participaram não somente dos cuidados dos filhos, como também de todo o período de gestação, como o parto de suas respectivas esposas. Este ocorrido vai ao encontro do que explica Freitas et al. (2009), que considerando o ingresso da mulher no mercado de trabalho, função considerada até então masculina, os homens passaram a compartilhar de algumas tarefas domésticas e também da educação de seus filhos. Entretanto, alguns pais ainda consideram o período de gestação, parto e amamentação como exclusivos da função feminina. Mais uma vez, as relações pautadas na divisão de papéis e relação de gênero são encontradas.

A paternidade também esteve relacionada às vivências e experiências que os "novos" pais tiveram, ainda enquanto filhos, com seus próprios pais. Aqueles que experimentaram um relacionamento frio e distante com os pais na infância, optaram por comportamentos opostos aos que vivenciaram, mostrando-se interessados em estabelecer um relacionamento afetivo com seus filhos, além de participar no cuidado e educação dos mesmos, conforme verificado por Bustamante (2005).

Deste modo, justifica-se este artigo na intenção de contribuir ainda mais com estudos e informações a respeito do que vem sendo produzido sobre o papel do pai na sociedade contemporânea brasileira, levando em consideração o que se tem preconizado na produção de trabalhos a respeito da paternidade. Com a sistematização de estudos brasileiros produzidos sobre a paternidade, fica evidente o quanto se tem pesquisado sobre este tema, a dimensão que a importância deste tema tem ganhado com o passar do tempo e a maneira pela qual a sociedade brasileira tem encarado a paternidade nos dias atuais.

Pode-se concluir com este artigo que a paternidade vem ganhando espaço e importâncias nos estudos científicos, sendo os pais considerados importantes para o desenvolvimento dos filhos e também para a família (relações conjugais). O modelo familiar e, consequentemente, o modelo de paternidade, têm se mostrado ora arraigados a conceitos/modelos antigos, ora aderindo comportamentos novos. Atualmente os pais estão sendo convidados a assumirem atribuições e demandas provenientes de uma nova sociedade - a sociedade atual -, que abriu espaço para novas conquistas femininas (inserção no mercado de trabalho) e masculinas (participação em atividades domésticas e no cuidado dos filhos). 


\section{REFERÊNCIAS}

ANDRADE, R. P.; COSTA, N. R. A.; ROSSETIFERREIRA, M. C. Significações de Paternidade Adotiva: um estudo de caso. Paidéia (Ribeirão Preto), Ribeirão Preto, v. 16, n. 34, p. 241-252, 2006. Disponível em: < http://www.scielo.br/pdf/paideia/v16n34/v1 6n34a12.pdf>. Acesso em: 15 nov. 2011. http://dx.doi.org/10.1590/S0103863X2006000200012.

BORNHOLDT, E. A.; WAGNER, A.; STAUDT, A. C. P. A vivência da gravidez do primeiro filho à luz da perspectiva paterna. Psicologia Clínica, Rio de Janeiro, v. 19, n. 1, p. 75-92, $2007 . \quad$ Disponível em: <http://www.scielo.br/pdf/pc/v19n1/06.pdf> . Acesso em:15 nov. 2011.

BUSTAMANTE, V. Ser pai no subúrbio ferroviário de Salvador: um estudo de caso com homens de camadas populares. Psicologia em Estudo, Maringá, v. 10, n. 3, p. 393-402, 2005. Disponível em: <http://www.scielo.br/pdf/pe/v10n3/v10n3a 06>. Acesso em: 15 nov. 2011.

BUSTAMANTE, V.; TRAD, L. A. B. Participação paterna no cuidado de crianças pequenas: um estudo etnográfico com famílias de camadas populares. Caderno de Saúde Pública, Rio de Janeiro, v. 21, n. 6, p. 18651874, 2005. Disponível em: <http://www.scielo.br/pdf/csp/v21n6/26.pdf $>$ Acesso em: 15 dnov. 2011.

BRASILEIRO, R. F.; JABLONSKI, B. B.; FÉRESCARNEIRO, T. Papéis de gênero, transição para a paternidade e a questão da tradicionalização. Psico, Porto Alegre, v. 33, n. 2, p. 289-310. 2002. BRUCHINI, M. C. A.; RIDENTI, S. Família, casa e trabalho. Cadernos de Pesquisa, São Luís, v. 1, n. 88, p. 30-36, 1994. Disponível em: < http://educa.fcc.org.br/pdf/cp/n88/n88a03.p $\underline{\mathrm{df}}>$. Acesso em: 15 nov. 2011.

CABRAL, C. S.. Contracepção e gravidez na adolescência na perspectiva de jovens pais de uma comunidade favelada do Rio de Janeiro. Cad. Saúde Pública, Rio de Janeiro, v. 19, supl. 2, 2003 . Disponível em: $<$ http://www.scielo.br/scielo.php?script=sci_ arttext\&pid=S0102-

$311 X 2003000800010 \& \operatorname{lng}=e n \& \mathrm{nrm}=$ iso $>$.

Acesso em: $\quad 15$ nov. 2011. http://dx.doi.org/10.1590/S0102-

311X2003000800010.

CARVALHO, M. L. M. Participação dos pais no nascimento em maternidade pública: dificuldades institucionais e motivações dos casais. Caderno de Saúde Pública, Rio de Janeiro, v. 19, n. 2, p. 389-398, 2003. Disponível em: < http://www.scielo.br/pdf/csp/v19s2/a20v19s 2.pdf>. Acesso em: 15 nov. 2011.

COSTA, N. R. A.; ROSSETI-FERREIRA, M. C. Tornar-se Pai em um Processo de Adoção Tardia. Psicologia: Reflexão e Crítica, Porto Alegre, v. 20, n. 3, p. 425-434, 2007. Recuperado em 15 de novembro, de 2011, de http://www.scielo.br/scielo

DANTAS, C.; JABLONSKI, B.; FÉRES-CARNEIRO, T. Paternidade: considerações sobre a relação pais-filhos após a separação conjugal. Paidéia, Ribeirão Preto, v. 14, n. 29, p. 347357, 2004. Disponível em: $<$ http://www.scielo.br/scielo.php?script=sci_ arttext\&pid=S0103-

$863 \times 2004000300010 \& \operatorname{lng}=e n \& \mathrm{nrm}=\mathrm{iso}>$.

Acesso em: 15 nov. 2011. http://dx.doi.org/10.1590/S0103863X2004000300010.

FERREIRA, N. S. A. As pesquisas denominadas "Estado da Arte". Educação \& Sociedade, Campinas, v. 23, n. 79, p. 257-272, 2002. Disponível em: http://www.scielo.br/pdf/es/v23n79/10857. pdf>. Acesso em: 15 nov. 2011.

FONSECA, C. A certeza que pariu a dúvida: paternidade e DNA. Revista Estudos Feministas, Florianópolis, v. 12, n. 2, p. 1334, 2004. Disponível em: < 
<http://www.scielo.br/pdf/ref/v12n2/23958. pdf>. Acesso em: 15 nov. 2011.

FREITAS, W. M. F. et al. Paternidade: responsabilidade social do homem no papel de provedor. Revista de Saúde Pública, São Paulo, v. 43, n. 1, p. 85-90, 2009. Disponível em:

http://www.scielo.br/pdf/rsp/v43n1/6868.pd f>. Acesso em: 15 nov. 2011.

FREITAS, W. M. F.; COELHO, E. A. C.; SILVA, A. T. M. C. Sentir-se pai: a vivência masculina sob o olhar de gênero. Caderno de Saúde Pública, Rio de Janeiro, v. 23, n. 1, p.137-145, 2007.

GOMES, A. J. S.; RESENDE, V. R. O pai presente: o desvelar da paternidade em uma família contemporânea. Psicologia: Teoria e Pesquisa, Brasília, v. 20, n. 2, p. 119-125, 2004. Disponível em: < http://www.scielo.br/pdf/ptp/v20n2/a04v20 n2.pdf>. Acesso em: 15 nov. 2011.

HENNINGEN, I. Especialistas advertem: o pai é importante para o desenvolvimento infantil. Fractal: Revista de Psicologia, Niterói, v. 22, n. 1, p. 169-184, 2010. Disponível em: < http://www.scielo.br/pdf/fractal/v22n1/v22n 1a13.pdf>. Acesso em: 15 nov. 2011.

HENNINGEN, I.; GUARESCHI, N. M. F. A paternidade na contemporaneidade: um estudo de mídia sob a perspectiva dos estudos culturais. Psicologia \& Sociedade, Minas Gerais, v. 14, n. 1, p. 44-68, 2002. Disponível em:

http://www.scielo.br/pdf/psoc/v14n1/v14n1 a04.pdf>. Acesso em: 15 nov. 2011.

KROB, A. D.; PICCININI, C. A.; SILVA, M. R. A transição para a paternidade: da gestação ao segundo mês de vida do bebê. Psicologia USP, São Paulo, v. 20, n. 2, p. 269-291, 2009. LUZ, A. M. H.; BERNI, N. I. O. Processo de paternidade na adolescência. Revista
Brasileira de Enfermagem, Brasília, v. 63, n. 1, p. 43-50, 2010.

LUZ, A. M. H.; ZANETTI, L. O conto de fada e da paternidade moderna. Revista Brasileira de Enfermagem, Brasília, v. 56, n. 3, p. 292297, 2003. LEVANDOWSKI, D. C.; PICCININI, C. A. A Interação Pai-Bebê entre Pais Adolescentes e Adultos. Psicologia: Reflexão e Crítica, Porto Alegre, v. 15, n. 2, p. 413-424, 2002.

LEVANDOWSKI, D. C.; PICCININI, C. A. Expectativas e Sentimentos em Relação à Paternidade entre Adolescentes e Adultos. Psicologia: Reflexão e Crítica, Porto Alegre, v. 22, n. 1, p. 17-28, 2006.

LEVANDOWSKI, D. C.; PICCININI, C. A.; LOPES, R. C. S. O processo de SeparaçãoIndividuação em Adolescentes do Sexo Masculino na Transição para a Paternidade. Psicologia: Reflexão e Crítica, Porto Alegre, v. 22, n. 3, p. 353-361, 2009.

MARTINELLI, V.; LO BIANCO, A. C. Viver bem no mal: a ética psicanalítica da paternidade. Psicologia Clínica, Rio de Janeiro, v. 10, n. 2, p. 143-159, 2006.

MEINCKE, S. M. K.; CARRARO, T. E. Vivência da paternidade na adolescência: sentimentos expressos pela família do pai adolescente. Texto e Contexto Enfermagem, Florianópolis, v. 18, n. 1, p. 83-91, 2009.

MOREIRA, J. O.; BORGES, A. A. P. A castração e seus destinos na construção da paternidade. Psicologia Clínica, Rio de Janeiro, v. 22, n. 2, p. 71-81, 2010. ORLANDI, R.; TONELI, M. J. F. Adolescência e Paternidade: sobre os direitos de criar projetos e procriar. Psicologia em Estudo, Maringá, v. 13, n. 2, p. 317-326, 2008.

PEROSA, C. T.; PEDRO, E. N. R. Perspectivas de jovens universitários da Região Norte do Rio Grande do Sul em relação à paternidade. 
Revista da Escola de Enfermagem da USP, São Paulo, v. 43, n. 2, p. 300-306, 2009.

PERUCCHI, J.; BEIRÃO, A. M. Novos arranjos familiares: paternidade, parentalidade e relações de gênero sob o olhar de mulheres chefes de família. Psicologia Clínica, Rio de Janeiro, v. 19, n.2, p. 57-69, 2007. PICCININI, C. A. et al. Expectativas e sentimentos de pais em relação ao bebê durante a gestação. Estudos de Psicologia, Campinas, v. 26, n. 3, p. 373-382, 2009.

PONTES, C. M.; ALEXANDRINO, A. C.; OSÓRIO, M. M. Participação do pai no processo da amamentação: vivências, conhecimentos, comportamentos e sentimentos. Jornal de Pediatria, Rio de Janeiro, v. 84, n. 8, p. 357364, 2008.

PONTES, C. M.; ALEXANDRINO, A. C.; OSÓRIO, M. M. O envolvimento paterno no processo da amamentação: propostas de incentivo. Revista Brasileira Saúde Materno Infantil, Boa Vista, v. 9, n. 4, p. 399-408, 2009.

SILVA, M. R.; PICCININI, C. A. Sentimentos sobre a paternidade e o envolvimento paterno: um estudo qualitativo. Estudos de Psicologia, Campinas, v. 24, n. 4, p. 565-573, 2007.

SILVA, M. R.; PICCININI, C. A. Paternidade no contexto da depressão pós-parto materna: revisando a literatura. Estudos de Psicologia, Campinas, v. 14, n. 1, p. 5-12, 2009.

SOUZA, C. L. C.; BENETTI, S. P. C. Paternidade contemporânea: levantamento da produção acadêmica no período de 2000 a 2007. Paidéia, Ribeirão Preto, v. 19, n. 42, p. 97106, 2009.

TRINDADE, Z. A.; MENANDRO, M. C. S. Pais adolescentes: vivência e significação. Estudos de Psicologia, Campinas, v. 7, n. 1, p. 15-23, 2002.
TRONCHIN, D. M. R.; TSUNECHIRO, M. A. Cuidar e o conviver com o filho prematuro: a experiência do pai. Revista latino-americana de Enfermagem, Ribeirão Preto, v. 14, n. 1, p. 93-101, 2006.

THURLER, A. L. Outros horizontes para a paternidade brasileira no século XXI? Sociedade e Estado, Brasília, v. 21, n. 3, p. 681-707, 2006. 